Otterbein University

Digital Commons @ Otterbein

Business, Accounting and Economics Faculty

Scholarship

Business, Accounting and Economics

Summer 2013

\title{
An Analysis of Managers' Resource Allocation Dilemma in a Fixed Ca pacity Situation
}

Michael Levin

Otterbein University

Follow this and additional works at: https://digitalcommons.otterbein.edu/bus_fac

Part of the Accounting Commons

\section{Repository Citation}

Levin, Michael, "An Analysis of Managers' Resource Allocation Dilemma in a Fixed Ca pacity Situation" (2013). Business, Accounting and Economics Faculty Scholarship. 3.

https://digitalcommons.otterbein.edu/bus_fac/3

This Article is brought to you for free and open access by the Business, Accounting and Economics at Digital Commons @ Otterbein. It has been accepted for inclusion in Business, Accounting and Economics Faculty Scholarship by an authorized administrator of Digital Commons @ Otterbein. For more information, please contact digitalcommons07@otterbein.edu. 


\title{
Research Note
}

\section{AN ANALYSIS OF MANAGERS' RESOURCE ALLOCATION DILEMMA IN A FIXED CAPACITY SITUATION}

\author{
Michael A. Levin, Robert E. McDonald, and James B. Wilcox
}

\begin{abstract}
Managers of museums, repertory theaters, sports leagues, and symphony orchestras invest resources in order to optimize attendance over a season. They must choose between investing resources evenly across a balanced portfolio of offerings or disproportionately concentrating resources on a few more desirable offerings at the expense of the rest of the portfolio. The better strategy is not always apparent. The authors investigate this research question in non-major league sports leagues using the Gini coefficient, a measure of equality/balance adapted from the field of economics. The spread of team success in a league, based on winning percentages and represented by the Gini coefficient, is used as an indicator of resource investment concentration. The findings indicate that availability, that is, season length, influences whether consumers value more a balanced or unbalanced investment strategy.
\end{abstract}

Traditional portfolio investment decisions involve allocating resources among several business units, product lines, or brands (e.g., Day 1977; Gupta 1987; Wind, Mahajan, and Swire 1983) in order to maximize current and future value to the firm. Managers invest resources to achieve performance outcomes that will enable them to compete at the product level against firms offering similar products. In contrast, consider the portfolio decisions of managers of museums, symphony orchestras, theaters, opera companies, and sports leagues; these managers allocate resources with the goal of optimizing attendance and revenue by competing at the consumer budgetary level. In other words, they compete for a larger share of customers' discretionary, entertainment budget.

In both instances, working within a budget, decision makers allocate available resources among the various elements in the portfolio. The effects of these decisions are reflected in performance outcomes such as changes in sales or attendance. The investment decision impact lead-

Michael A. Levin (Ph.D., Texas Tech University), Assistant Professor of Marketing, College of Professional Studies, Otterbein University, Westerville, OH, mlevin@otterbein.edu.

Robert E. McDonald (Ph.D., University of Connecticut), Associate Professor of Marketing, Rawls College of Business, Texas Tech University, Lubbock, TX, bob.mcdonald@ttu.edu.

James B. Wilcox (DBA, University of Indiana), Professor of Marketing, Rawls College of Business, Texas Tech University, Lubbock, TX, jim.wilcox@ttu.edu. ing to increased sales for a firm could be in the form of an aggressive promotional campaign, a product innovation, or a more complete product line. For an arts or entertainment organization, the impact of the allocation decision might be a season containing one or two spectacular events among the season's offerings or, alternatively, a more balanced approach where the events are relatively equal in appeal to consumers.

Which of these investment strategies is likely to lead to higher attendance for an arts or entertainment organization? Should the manager allocate a disproportionate amount of the resources to one of the performances or events or allocate the resources evenly across all of the market offerings? Does availability affect the efficacy of the different allocation schemes, that is, is the same strategy appropriate for a season with a few events such as a repertory theater and a season with many events or a museum that is open year round? Much less scholarly insight is available on this form of portfolio allocations relative to traditional portfolio management. The purpose of this study is to empirically investigate these questions. We focus on the effect of the resource allocation decision and the resulting performance outcome. Should the effect be a balanced portfolio or imbalanced portfolio in terms

The authors thank David J. Berri, Robert E. Malchman, and Greg W. Marshall and the three anonymous reviewers, who provided much appreciated assistance in shaping the final draft of this paper. 
of the relative attractiveness of the offerings to consumers? Using total attendance at sporting events in a league as the performance outcome, we adopt a traditional measure of balance/imbalance from the field of economics, the Gini coefficient to measure the effect of the resource allocation decision. The subject of balanced portfolios been studied extensively in professional sports.

\section{PORTFOLIO BALANCE}

The focal question of this research is whether or not to balance the cultural or entertainment entity's portfolio of market offerings. For a sports league, balance is the relative equality of the teams in the league in terms of competitiveness. "Competitive balance represents uncertainty about the outcome of professional sporting events" (Humphreys 2002 , p. 133). This uncertainty is inherently valuable to consumers as a more competitive game promises to be more entertaining (Borland and Lye 1992; Humphreys 2002; Hynds and Smith 1994; Knowles, Sherony, and Haupert 1992; Neale 1964).

Competitive balance is the state where the teams in the league are equal in terms of talent and therefore games between two teams are likely to be vigorously contested. The general belief is that games or matches between two equal teams will be more exciting and therefore more enjoyable in large part because the outcome is uncertain (Neale 1964). Ceteris paribus, competitive balance in sports is a reflection of the distribution of player talent among the teams in the league (Ryczek 1992). League managers strive to achieve balance among the teams in their leagues largely by managing resources-in this case, player talent. Player drafts and salary caps are two mechanisms that league managers use to allocate player resources among teams to achieve competitive balance (Levin and McDonald 2009; Meehan, Nelson, and Richardson 2007).

This balance has been studied in Major League Baseball (Humphreys 2002; Knowles, Sherony, and Haupert 1992; Schmidt and Berri 2001), the National Basketball Association (Berri, Schmidt, and Brook 2004), Australian Rules Football $<$ IS THIS THE FORMAL NAME? (I.E., SHOULD RULES FOOTBALL BE UPPERCASE OR LOWERCASE?>> (Borland 1987; Borland and Lye 1992), the 1996 European soccer championship tournament<<OKAY AS IS, OR IS THERE A FORMAL NAME FOR THIS? > (Baimbridge 1997), Rugby League (Carmichael, Millington, and Simmons 1999), and international test match cricket<<OKAY AS IS, OR IS THERE A FORMAL NAME FOR THIS?>> (Hynds and Smith 1994). Generally, these studies have found that competitive balance leads to increased attendance. However, Berri, Schmidt, and Brook (2004) did not find a significant relationship between balance and attendance. It is possible that the effect of balance is overshadowed by the other 22 variables in the study such as all-star players, venue age, and league expansion.

Two studies found notable effects of time or availability operationalized as season length and number of seasons of analysis. Baimbridge (1997) used a nonlinear measure of the balance trend to determine the number of matches in a tournament to optimize attendance. Schmidt and Berri (2001) found that in the short term, season to season, balance actually has a negative effect on attendance, but over a longer term, three to five seasons, balance has a positive effect. Season lengths in the various sports studied vary widely. Australian Rules Football<<UPPERCASE CORRECT FOR "RULES FOOTBALL"? > teams play 22 games per season, for example, whereas Major League Baseball teams plays 162 . Given this disparity, it is possible that the effect of balance may be moderated by season length or availability.

Balance is measured in a number of ways, including relative standard deviation of win-loss records, standard deviation of team records against a theoretical perfect balance, Lorenz curves, Hirfindahl-Hirschman indexes $<<$ THE COMBINED INDEX OR HIRFINDAHL AND HIRSCHMAN INDEXES?〉>, and competitive balance ratio (Humphreys 2002). Borland and Lye (1992) use a comparison of the number of matches necessary to reach the playoffs as a measure of balance. Betting odds are used as a proxy for balance in studies in baseball (Knowles, Sherony, and Haupert 1992) and rugby (Carmichael, Millington, and Simmons 1999).

Schmidt and Berri chose to measure balance by using, "the conventional economic measure of inequality, the GINI<<UPPERCASE AS IN ORIGINAL?〉> coefficient" (2001, p. 47). They found similar results using a method that calculates balance using standard deviations of records, but chose to use Gini because it "is a common and rudimentary unit of measurement where questions of inequality are central. More specifically, the coefficient provides a single unit measure for the degree to which a relationship deviates from equality. Given that equality represents perfect competitive balance, the measure captures much of the literature's intuition" (Schmidt and Berri 2001, p. 47). For these reasons, we also choose the Gini coefficient to represent inequality or imbalance among teams in a league. The range of values for the Gini coefficient are defined as between 0 and 1 , where 0 represents perfect balance or a 
league with every team having the same record and 1 represents the greatest degree of imbalance.

For a repertoire theater company, balance might be a season of plays of relatively equal appeal to theater patrons. An imbalanced season might offer one blockbuster play, perhaps with a famous guest star, to draw large crowds. The risk of the latter strategy is that the resources remaining after producing the hit play might be so low that the company can afford to produce only relatively unattractive plays for the rest of the season. This could lead to poor attendance for the majority of the plays, and perhaps decrease the overall season attendance.

Faced with this decision, managers make different choices. For example, the Kimball Art Museum rented an exhibit from the Art Institute of Chicago for $\$ 2$ million. The acting director of the museum, Malcolm Warner, justified the decision based on the number of people who were expected to attend the exhibit (Green 2008). Warner decided a spectacular attraction would draw more patrons to visit the Kimball. In contrast to Warner's decision, Michael Brand, the director of the Virginia Museum of Fine Arts, elected to spread his organization's resources over many collections (Goodheart 2003). Each collection would attract its own set of visitors, who otherwise might not frequent the museum.

Marketing research has long shown an interest in the marketing of entertainment. Past studies have examined ticket sales for movie theater (Ainslie, Drèze, and Zufryden 2005), art theaters (Voss and Voss 2000), and major league baseball (Holt 1995). Each of these instances involves a process of "prosumption," whereby the consumer is actively engaged in the production of their own experience (Xie, Bagozzi, and Troye 2008). Furthermore, unlike other forms of prosumptive services, these and other hedonic experiences involve a high degree of emotion, so consumer purchase decisions are likely to have strong affective influences (Hirschman and Holbrook 1982). What is lacking from this research is an investigation of ways that managers of organizations that offer experiential consumption can increase attendance, to optimize consumption levels of their market offerings within the given spatial and temporal availability limits.

The extant literature on hedonic consumption (e.g., Hirschman and Holbrook 1982) gives us an understanding of consumption for pleasure or enjoyment. There are a number of ways that the consumption of arts and entertainment performances can be enjoyable. Deighton (1992) suggests four types of performances that attract the attention of consumers: skill, thrill, show, and festive performances. In skill and show performances the consumer pays to see enter- tainers perform, that is, the consumer takes on a passive, observational role in the service consumption. Attending a play, opera, or the ballet are examples of this kind of performance. In thrill and festive performances, the consumer pays to be entertained and, in this setting, takes on a more active, participatory role in the service consumption such as watching a baseball game (Holt 1995) or participating in a street fair. As Kelley, Hoffman, and Carter noted, skill and thrill performances can occur in the natural setting of $<<.$. . OF, SAY, A...? >> a professional hockey game, "with tension and uncertainty and circumstances leading to the testing of values" (1999, p. 477).

In team sports, league managers must allocate the players and set the rules in such a fashion that the performance by the players will be compelling to some segment of consumers. Hence, a game in which both teams appear equally matched would likely appeal to consumers who appreciate skill or thrill (Whitney 1988). Ancillary elements such as fan contests, opening ceremonies, jersey retirements, and old-timer games might even appeal to fans seeking festive or show performances. The core element of marketing culture and entertainment is the experience that consumers buy (Holt 1995). Despite being exposed to the same offering, each consumer's experience is unique. Consumption experience, taste, and mood might influence how an individual will experience the offering. Although the manager has no direct control over each consumer's experience, the manager retains control over qualities of the offerings that may influence how enjoyable consumers may find a particular offering. This level of enjoyment may be a function of the skill involved in the performance. It may also be influenced by the thrill of the performance, such as a tightly contested ball game where the opponents are so evenly matched that the outcome is uncertain until nearly the end of the game.

Sport as a sample domain has been used to examine topics germane to marketing strategy, including loyalty (Adler and Adler 1988), motivation and performance (Bloom 1999), new product development (Takeuchi and Nonaka 1986), and resource-based view of the firm (Poppo and Weigelt 2000). Goff and Tollison (1990, pp. 3-14) discuss three advantages to using sports as a sample domain:

1. The availability of data due to the frequency and regularity of athletic events, transparency of changes in strategies and processes, and clarity of outcomes results in unique opportunities to observe, measure, and compare variables and relationships of interest over time. 
2. Although organizational research must frequently test hypotheses using proxies for measures, many relevant variables are measured with great accuracy in sport as sport leagues tend to be prolific data collectors.

3. Doing research within a sports context mimics laboratory research in that hypotheses can be tested in relatively controlled field conditions. Moreover, sport overcomes the laboratory research challenges of having motivated participants as fans are intrinsically motivated by the skill and thrill of competition.

In short, sport offers strategy and resource-based researchers an opportunity to collect data that is accurately recorded and examines changes in variables over time (Wolfe et al. 2001).

The data used in this study come from the Arena Football League (AFL), the Central Hockey League (CHL), the Major Indoor Soccer League (MISL), the National Lacrosse League (NLL), and the Northern (baseball) League (NL). All of the league statistics are computed from league inception through the 2008-9 seasons. Four of these five leagues the NL, CFL, MISL, and NLL, have international competitions similar to football's World Cup $<<$ OKAY, OR SOCCER (CONSIDERING A MOSTLY, BUT NOT ALL OF COURSE, U.S. READERSHIP)? THE FIFA WORLD CUP?〉>. The AFL, MISL, and NLL represent the highest level of their respective sports: indoor American football, indoor soccer, and indoor lacrosse. The other two leagues, the CHL and the NL, have no formal associations with respective major league organizations in hockey and baseball, that is, they are not minor leagues, comprised of farm teams. Minor leagues, those with formal associations with major league organizations such as those found in baseball, focus on player development rather than league championships. In turn, management's concern is on the athlete's progress as opposed to team performance optimization. Team managers in nonmajor professional leagues focus on winning the league's championship. This study uses archival data gathered from league Web sites and media guides.

Since none of these leagues exists to develop players in support of a higher level league, each must be self-sufficient and is therefore motivated to maximize profits. This motivation makes the outcome of the study more generalizable than one using minor leagues. The other advantage to using non-major sports leagues is that they are influenced to a lesser degree by factors such as broadcast revenues that are so important to major leagues and school spirit that drives fan loyalty for college sports (Levin and McDonald 2009).
Focusing on these leagues helps to isolate the effects of competitive balance on attendance.

\section{CONSTRUCTS AND MEASURES}

\section{Demand}

To explore attendance, data collected from five non-major leagues (Johnson 1995) are utilized. Because these sports leagues use different venues and offer differing number of opportunities to consume, we operationalize demand as the average utilization rate of sports venues of the teams in a league. Specifically, average utilization rate is defined as

$$
\frac{\left(\frac{\sum \text { Attendance }_{w}}{\sum \text { Games }_{w}}\right)}{\left(\frac{\sum \text { Capacity }_{i w}}{n_{w}}\right)},
$$

where the sum of attendance for season $w$ is divided by the number of home games for season $w$, and the sum of venue capacity for team $i$ playing in season $w$ is divided by the total number of teams $n$ for season $w$. This measure allows for a comparison of two or more leagues that have heterogeneous venue sizes, numbers of teams, and season lengths. We tested whether or not the fixed capacity of the venues limited attendance, that is, set an upper bound on sales that would affect the validity of the study. We found that the average arena utilization was only 55 percent, with a standard deviation of 14 percent. Thus, demand for the league's form of entertainment could be considered satiated, and the venue size is likely not a constraining factor.

\section{League Balance}

Portfolio balance for a cultural or entertainment organization would mean that each of its offerings is roughly equal in terms of appeal to consumers. In other words, consumers are not likely to be drawn to one performance or event more so than they are to the other performances and events offered that season. In an imbalanced portfolio, consumers would be drawn to one or a few performances more so than the others. In the domain of non-major league professional sports, we operationalize this construct using the Gini coefficient to represent the relative distribution of win/loss records of the teams in the league. Since team performance is generally a function of player talent, a team resource (Schmidt and Berri 2001), this distribution is indicative of the concentration of resource investment. A low Gini value indicates that the teams are more evenly matched, 
likely as a result of evenly invested resources. A high Gini value indicates that the teams are likely unbalanced, with a disproportionate amount of resources concentrated in few teams. The concern is whether broad investment of resources leading to competitive balance in the league will lead to higher value than competitive imbalance resulting from disproportionate investing in relatively few teams.

Presumably, consumers enjoy seeing their team win rather than lose, but from a league perspective, it is the variability of the won/loss records that is of interest in this research. With more teams vying for the championship, consumer interest would likely be higher across the league. Therefore, evenly matched teams (i.e., those with comparable won/loss records) across the league should lead to greater total attendance, whereas more disparate records would not draw as many fans. Fans buy tickets to games based on their expectation of their enjoyment of the experience. The literature supports the idea that fans may use the competitive balance between two teams as an indicator of how enjoyable a game will be. Therefore, they may be more likely to attend a game between two evenly matched opponents.

We use the Gini coefficient here as a measure of the distribution of winning percentages, or success rates, of the various teams in their respective leagues. While there are many measures of balance that have been used, Gini is an appropriate representation of the distribution of success. Gini indicates the result of the decision of how to allocate league resources. The Gini coefficient was used by Lambert (1993) to examine income concentration among a population. It has also been used to rate the happiness of countries<<IS "HAPPINESS OF COUNTRIES" CORRECT?>> (Brooks 2007) as well as to measure the quality of Major League Baseball's product (Schmidt 2001; Schmidt and Berri 2001). Following Lambert (1993), Milanovic (1997), and Schmidt (2001), we use the following formula to determine the Gini coefficient $(G)$ :

$$
\begin{aligned}
& G_{i}=\left(1+\frac{1}{N_{i}}\right)-\frac{2}{\mathrm{~N}_{i}^{2} \mu_{x_{i}}} *\left(x_{N, i}+2 * x_{N-1, i}+3 * x_{N-2, i}\right. \\
& \left.+K+N * x_{1, i}\right),
\end{aligned}
$$

where, $N$ represents the number of teams, $x_{N}$ represents the winning percentage of team $\mathrm{N}, \mu$ represents the mean of $x$, and $i$ represents the time period. Each team is ranked relative to its winning percentage so that $x_{N} \geq x_{N-1} \geq \ldots \geq x_{1}$ and the percentages are weighted by their respective ranks. The Gini coefficient provides a linear measure of distribution ranging from zero to one, with zero representing perfect equality. Therefore, as Gini approaches zero, the teams in the league approach competitive balance. As it approaches one, the teams become more imbalanced competitively.

It should be noted that this is not just a fixed or ordinal measure; rather, Gini is a relative measure. The distance of member A's $x_{N}$ from member B's $x_{N}$ is not likely the same distance as member B's $x_{N}$ from member C's $x_{N}$. So the winning percentages of the three teams may be 65 percent, 60 percent, and 50 percent, respectively. Furthermore, the order of finish, based on teams' winning percentage, affects the Gini coefficient, regardless of whether teams finish within one or ten percentage points of each other.

Hypothesis 1: The value of the Gini coefficient will be inversely related to the total attendance (capacity utilization) for the season.

\section{Availability}

The number of opportunities to consume arts or entertainment offerings may influence consumers' behaviors. While consumers have been found to postpone the consumption of even enjoyable experiences in large part due to temporal discounting, they are likely to act when faced with a time constraint (Shu and Gneezy 2010). This latter finding may be due to the scarcity effect (Brock 1968<<NOT IN REFERENCE LIST >), which is the risk that the opportunity to consume could be lost if they do not act soon. This conclusion could predict that balance will not be as important when the opportunities to consume are fewer. Studies in sports have found that the number of games played might influence the effect of balance (e.g., Baimbridge 1997), implying that the season length might be a variable of interest. For a theater, this could refer to the number of different plays and the number of performances each play will run. We are interested in how availability might influence the effectiveness of difference resource allocation strategies.

Hypothesis 2: The relationship between the Gini coefficient and the total attendance (capacity utilization) will be weaker for shorter seasons.

\section{METHOD}

This research note tests the relationship of the relative balance of the offerings as represented by Gini, availability as represented by the number of games in a season, and the interaction effect between these two variables as they influence the facility utilization rate, that is, attendance. Because the league is the unit of analysis, all of the variables are measured at the league level. 
Table 1

Summary of Sample

\begin{tabular}{|c|c|c|c|c|c|}
\hline League & Seasons & $\begin{array}{l}\text { Average } \\
\text { Number } \\
\text { Teams* }\end{array}$ & $\begin{array}{l}\text { Average } \\
\text { Games/ } \\
\text { Season* }\end{array}$ & Games & $\begin{array}{c}\text { Team } \\
\text { Seasonal } \\
\text { Records }\end{array}$ \\
\hline Arena Football League & 19 & 12.5 & 82.7 & 1,572 & 237 \\
\hline Central Hockey League & 17 & 12.4 & 400.8 & 6,813 & 210 \\
\hline Major Indoor Soccer League & 23 & 9.7 & 185.0 & 4,254 & 224 \\
\hline National Lacrosse League & 23 & 8.2 & 52.8 & 1,214 & 189 \\
\hline Northern League & 16 & 8.1 & 354.7 & 5,675 & 130 \\
\hline Total & 98 & 10.1 & 199.6 & 19,528 & 990 \\
\hline
\end{tabular}

\section{Data}

Archival data were gathered from league Web sites and media guides, with gaps supplemented by telephone and e-mail requests, to provide total attendance, arena capacity, and total home games. The five nonmajor professional sports leagues are the Arena Football League (AFL), the Central Hockey League (CHL), the Major Indoor Soccer League (MISL), the National Lacrosse League (NLL), and the Northern League (NL), which plays baseball, but is not affiliated with Major League Baseball. The utilization rate and Gini coefficient data were transformed by taking the arcsine of the square root of the original value. This transformation addresses the possibility of heteroskedasticity inherent in the variance of fractional data (Downward and Dawson 2000). In total, 990 team seasonal records, representing 19,528 games, were compiled to generate 98 league seasons of aggregated data for analysis (Table 1).

\section{Results}

Although, in theory, the Gini coefficient can range from 0 , or perfectly equal, to 1 , or unequal, in this sample the Gini coefficient's lower limit is 0.05 and the upper limit is 0.35 . The league with a coefficient of 0.05 is the most competitively balanced, while that with a coefficient of 0.35 is least balanced. The data were analyzed using ordinary least squares regression. As shown in Table 2, all of the coefficients in the model were significant. The $R^{2}$ of 0.41 indicates that the model predicts a reasonable amount of variance in attendance.

In order to better present the behavior of utilization rates across quantity and quality, the regression coefficients were used to generate a response surface (Figure 1) by varying the season length from 5 to 95 games/team and Gini from 0.05 to 0.35 . It is clear that both balance and availability have a substantive effect on the utilization rate. As the number of games increases, the utilization rate decreases; as the Gini coefficient increases the utilization rate decreases, supporting H1. The interaction effect appears most interesting though. Leagues with very short seasons $\ll<$ WHAT DETERMINES A SHORT OF VERY SHORT SEASON?>> do not appear to be affected by a lack of competitiveness but as the season gets longer, the utilization rate falls rather dramatically, supporting H2. However, utilization rates can be maintained if the competitiveness increases along with the number of games.

\section{DISCUSSION}

\section{Managerial Implications}

Unlike previous portfolio models that investigate how firms strategically allocated resources among SBUs $<<$ DEFINE / STRATEGIC BUSINESS UNITS?>> or product lines for long-term profit maximization, the current study looks at short-term resource allocations among entertainment offerings to maximize attendance for an upcoming season. We compare the balance of the offerings in the portfolio represented by the theoretical competitiveness of two teams in this instance, with availability, measured by the number of games in a season. We find that during a longer season, attendance is higher when there is more balance among competitors. For short seasons, balance seems less important and may actually reduce league attendance. This interaction effect indicates that when availability is extensive, the thrill and skill promised by a game between two equally matched opponents is necessary to draw fans. 
Table 2

Estimated Coefficients (Dependent Variable Is Average Utilization Rate)

\begin{tabular}{lcccc}
\hline Variable & Coefficient & $\begin{array}{c}\text { Standard } \\
\text { Error }\end{array}$ & t-Statistic & $\boldsymbol{p}$-Value \\
\hline Intercept & -0.47 & 0.23 & -2.06 & 0.0420 \\
Gini & 3.48 & 0.51 & 6.84 & 0.0001 \\
Season Length & 0.48 & 0.07 & 7.21 & 0.0001 \\
Gini X Season Length & -1.28 & 0.16 & -7.85 & 0.0001 \\
Observations & 98 & & & \\
$R^{2}$ & 0.41 & & & \\
Adjusted $R^{2}$ & 0.39 & & & \\
F-Statistic & 21.3 & & & \\
$p$-Value & 0.000 & &
\end{tabular}

Notes: All coefficients are standardized. Several control variables were tested and found not to be significant. These were measures of population and income levels in each team's market and changes in the number of teams in each league.

\section{Figure 1}

\section{Gini and Attendance}

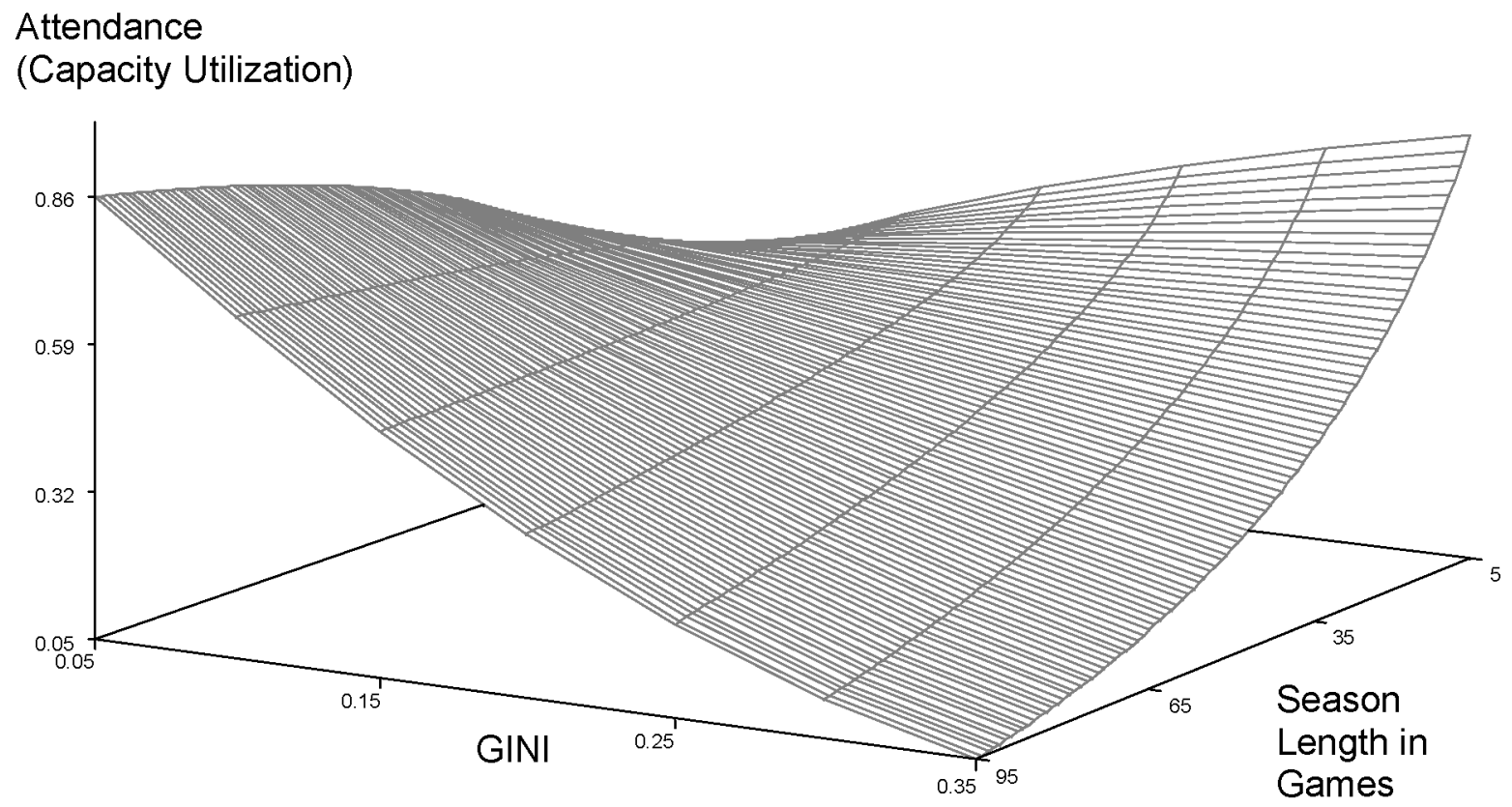

Yet when the season is short, fans are more likely to attend, despite balance as the limited availability prompts them to act<<SENTENCE OKAY?»〉.

From a resource allocation perspective, it appears that attendance can be influenced by matching the resource allocation strategy to the availability. For limited availability, it seems that a narrow, more focused allocation of resources is best. Attendance can be enhanced by offering one spectacular show. However, when the availability is long, a balanced allocation approach will provide better results in attendance by offering a wider variety of evenly matched offerings. A fuller understanding of the organization's customers and the values that drive their decision making, along with the organization's mission and strategic direction, will better guide the resource allocation decision process.

The results indicate an interesting phenomenon. As shown in Figure 1, attendance appears at its higher points, or peaks, when (1) fewer opportunities to consume exist and the relative value of the entertainment market offering appears less balanced and (2) many opportunities to consume exist and the entertainment market offering portfolio is well balanced. Also of note, although lower than when 
there is a concentration of in a few offerings leading to an imbalance in the portfolio, attendance appears fairly high when fewer opportunities to consume exist and the relative value of the entertainment market offering is balanced.

Interpreting these results, we can see that when customers have relatively many opportunities to consume, they place greater value, as indicated by attendance, on a portfolio of offerings with relatively well-balanced quality than one where resources are expended to provide a few offerings in the portfolio that have relatively higher entertainment value. Furthermore, when there are fewer opportunities to consumer, customers place greater value on portfolios with a few offerings that promise higher relative quality. Interestingly, in the limited consumption condition, the difference in attendance between a balanced and unbalanced portfolio is not as great as when there are many opportunities for consumption. So in short seasons, it may be worth investing in a few exciting offerings, but in long seasons, managers should seek to offer a balanced portfolio.

For entertainment firms that offer limited opportunities to consume, this research suggests an approach toward allocating resources to ensure higher attendance. For example, an amusement park manager whose operations are open for a few months out of the year should focus on a single ride such as an especially fast and roller coaster rather than ensuring that several rides offer above-average levels of enjoyment. A theater with a short season might consider hiring well-known actors or producing a powerful play or musical. A short season sports league such as the National Lacrosse League, which offers on average seven home games per season, could survive when one or two teams dominate the remaining teams.

For entertainment firms that offer many opportunities to consume, this research suggests a different approach to increase attendance. For example, a manager whose museum remains available year-round might do well to build the quality of the permanent collection. The manager of an amusement park that is open year-round, such as Disneyworld, should spread the investments across their venues instead of promoting a single attraction. Indeed, the higher quality of all Disney venues could be a key to its success in the entertainment industry. Similarly, a long season sports league such as the Central Hockey League, which offers, on average, 31 home games per season for each team, should ensure as many teams have a chance at the championship because consumers could lose interest if one or two teams appear dominant.

\section{Limitations and Future Research}

Data from sport leagues could appear as censured data because stadium capacity constrains how many people can attend an event. In turn, some fans could not attend an event because all tickets had been sold. However, for this research note's sample (nonmajor leagues), the data do not appear censured because no league reported 100 percent attendance. With the exception of one team in one league for one season, no team reported all games sold out for the season. If a fan wanted to attend a nonmajor professional league game or games, then tickets for the event or events were available.

Attendance at sporting events, and other entertainment offerings, may be influenced by different factors such as customer loyalty. Those that purchase season tickets, for example, might attend games that they would not otherwise attend (Soman and Gourville 2001). We chose non-major league sports leagues in large part to isolate the data from factors that are quite common in major league and college sports, including avid loyalty, school pride, and mass marketing appeals. Although we were not able to control for all such effects, we believe that the current data set offers a unique setting for this study.

Furthermore, this research note relies on available archival data. Additional variables such as the number of weekday and weekend contests and prices of tickets are not available. Attendance could increase for weekend games relative to weekday games. Data related to ticket prices is nonexistent for this data set. These two variables would provide additional insight if the data were available.

Finally, this study investigates balance at the seasonal level. Balance and attendance can be and has been studied at a narrower time level such as an individual game. One avenue for further research would be to study trends in attendance over a season in response to balance changes.

\section{CONCLUSION}

Fans enjoy a good game, one in which the teams are evenly matched. This competitive balance is more important over a longer season than a shorter one. The limited availability of a short season, such as a six-game college football schedule, prompts consumers to attend games while they are available, regardless of competitiveness. The implications of this study are that arts and entertainment providers with long seasons should seek to balance their offerings in terms of their appeal to consumers. 


\section{REFERENCES}

Adler, Patricia A., and Peter Adler (1988), "Intense Loyalty in Organizations: A Case Study of College Athletics," Administrative Science Quarterly, 33 (3), 401-417.

Ainslie, Andrew, Xavier Drèze, and Fred Zufryden (2005), "Modeling Movie Life Cycles and Market Share," Marketing Science, 24 (3), 508-517.

Baimbridge, Mark (1997), "Match Attendance at Euro 96: Was the Crowd Waving or Drowning?" Applied Economic Letters, 4 (9), 555-558.

Berri, David J., Martin B. Schmidt, and Stacey L. Brook (2004), "Stars at the Gate: The Impact of Star Power on NBA Gate Revenues," Journal of Sports Economics, 5 (1), 33-50.

Bloom, Matt (1999), "The Performance Effects of Pay Dispersion on Individuals and Organizations," Academy of Management Journal, 42 (1), 25-40.

Borland, Jeff (1987), "The Demand for Australian Rules Football," Economic Record, 63 (3), 220-230.

— ball: A Panel Study," Applied Economics, 24 (9), 1053-1058.

Brooks, Arthur C. (2007), "Happiness and Inequality," Wall Street Journal, October 22 (available at http://online.wsj.com/ article/SB119301749588666639.html).

Carmichael, Fiona, Janet Millington, and Roberts Simmons (1999), "Elasticity of Demand for Rugby League Attendance and the Impact of BskyB," Applied Economics Letters, 6 (12), 797-800.

« NOT CITED / CITE OR DELETE»>Cronin, J. Joseph, Jr., and Steven A. Taylor (1992), "Measuring Service Quality: A Reexamination and Extension," Journal of Marketing, 56 (3), 55-68.

Day, George S. (1977), "Diagnosing the Product Portfolio," Journal of Marketing, 41 (2), 29-38.

Deighton, John (1992), "The Consumption of Performance," Journal of Consumer Research, 19 (3), 362-72.

Downward, Paul, and Alistair Dawson (2000), The Economics of Professional Team Sports, New York: Routledge.

« NOT CITED / CITE OR DELETE〉> Fort, Rodney, and Joel Maxcy (2003), "Competitive Balance in Sports Leagues: An Introduction," Journal of Sports Economics, 4 (2), 154-160.

Goff, Brian L., and Robert D. Tollison (1990), Sports as Economics, College Station: Texas A\&M University Press.

Goodheart, Adam (2003), "Moving Up; In Richmond, a Museum Aims for the Big Leagues," New York Times, April 23 (available at www.nytimes.com/2003/04/23/arts/movingup-in-richmond-a-museum-aims-for-the-big-leagues. html?pagewanted=all\&src=pm).

Green, Tyler (2008), "Pay Per View," Upstart, May 12 (available at http://upstart.bizjournals.com/culture-lifestyle/culture-inc/ arts/2008/05/12/Art-Museums-Charging-Big-Fees.html).

« NOT CITED / CITE OR DELETE»> Grove, Stephen J., Raymond P. Fisk, and Michael J. Dorsch (1998), "Assessing the Theatrical Components of the Service Encounter: A Cluster Analysis Examination," Service Industries Journal, 18 (3), 116-134.

Gupta, Anil K. (1987), "SBU Strategies, Corporate-SBU Relations, and SBU Effectiveness in Strategy Implementation," Academy of Management Journal, 30 (3), 477-500.

Hirschman, Elizabeth C., and Morris B. Holbrook (1982), "Hedonic Consumption: Emerging Concepts, Methods and Propositions," Journal of Marketing, 46 (3), 92-101.
< NOT CITED / CITE OR DELETE» Holbrook, Morris B., Robert W. Chestnut, Terence A. Oliva, and Eric A. Greenleaf (1984), "Play as a Consumption Experience: The Roles of Emotions, Performance, and Personality in the Enjoyment of Games," Journal of Consumer Research, 11 (2), 728-739.

Holt, Douglas B. (1995), "How Consumers Consume: A Typology of Consumption Practices," Journal of Consumer Research, 22 (1), 1-16.

Humphreys, Brad A. (2002), "Alternative Measures of Competitive Balance in Sports Leagues," Journal of Sports Economics, 3 (2), 133-148.

Hynds, Michael, and Ian Smith (1994), "The Demand for Test Match Cricket," Applied Economic Letters, 1 (7), 103-106.

Johnson, Arthur T. (1995), Minor League Baseball and Local Economic Development, Urbana: University of Illinois Press.

Kelley, Scott W., K. Douglas Hoffman, and Sheila Carter (1999), "Franchise Relocation and Sport Introduction: A Sports Marketing Case Study of the Carolina Hurricanes' Fan Adoption Plan," Journal of Services Marketing, 13 (6), 469-480.

Knowles, Glenn, Keith Sherony, and Mike Haupert (1992), "The Demand for Major League Baseball: A Test of the Uncertainty of Outcome Hypothesis," American Economist, 36 (2), 72-80.

Lambert, Peter J. (1993), The Distribution and Redistribution of Income: A Mathematical Analysis, Manchester: Manchester University Press.

Levin, Michael A., and Robert E. McDonald (2009), "The Value of Competition: Competitive Balance as a Predictor of Attendance in Spectator Sports," International Journal of Sports Marketing \& Sponsorship, 11 (1), 7-24.

Milanovic, Branko (1997), "A Simple Way to Calculate the Gini Coefficient and Some Implications," Economic Letters, 56 (1), 45-49.

Meehan, James W., Jr., Randy A. Nelson, and Thomas V. Richardson (2007), "Competitive Balance and Game Attendance in Major League Baseball," Journal of Sports Economics, 8 (6), 563-580.

Neale, Walter C. (1964), "The Peculiar Economics of Professional Sports: A Contribution to the Theory of the Firm in Sporting Competition and in Market Competition," Quarterly Journal of Economics, 79 (1), 1-14.

< NOT CITED / CITE OR DELETE > Parasuraman, A., Valarie A. Zeithaml, and Leonard L. Berry (1985), "A Conceptual Model of Service Quality and Its Implications for Future Research," Journal of Marketing, 49 (4), 41-50.

Poppo, Laura, and Keith Weigelt (2000), "A Test of the ResourceBased Model Using Baseball Free Agents," Journal of Economics \& Management Strategy, 9 (4), 585-614.

Ryczek, William J. (1992), Blackguards and Red Stockings: A History of Baseball's National Association, Jefferson, NC: McFarland.

Schmidt, Martin B. (2001), "Competition in Major League Baseball: The Impact of Expansion," Applied Economic Letters, 8 (1), 21-26.

and David J. Berri (2001), "Competitive Balance and Market Size in Major League Baseball: A Response to Baseball's Blue Ribbon Panel," Review of Industrial Organization, 21 (1), 41-54.

Shu, Suzanne B., and Ayelet Gneezy (2010), "Procrastination of Enjoyable Experiences," Journal of Marketing Research, 47 (October), 933-974. 
Soman, Dilip, and John T. Gourville (2001), "Transaction Decoupling: How Pricing Bundling Affects the Decision to Consumer," Journal of Marketing Research, 38 (1), 30-44.

Takeuchi, Hirotaka, and Ikujiro Nonaka (1986), "The New New Product Development Game," Harvard Business Review, 64 (January), 137-146.

<<NOT CITED / CITE OR DELETE〉> Thwaites, Des (1999), "Closing the Gaps: Service Quality in Sport Tourism," Journal of Services Marketing, 13 (6), 500-516.

$<$ <OT CITED / CITE OR DELETE > Utt, Joshua, and Rodney Fort (2002), "Pitfalls to Measuring Competitive Balance with Gini Coefficients," Journal of Sports Economics, 3 (4), 367-373.

Voss, Glenn B., and Zannie Giraud Voss (2000), "Strategic Orientation and Firm Performance in an Artistic Environment," Journal of Marketing, 64 (1), 67-83.

Whitney, James D. (1988), “Winning Games Versus Winning Championships: The Economics of Fan Interest and Team Performance," Economic Inquiry, 26 (4), 703-724.
Wind, Yoram, Vijay Mahajan, and Donald J. Swire (1983), "An Empirical Comparison of Standardized Portfolio Models," Journal of Marketing, 47 (Spring), 89-99.

Wolfe, Richard A., Karl E. Weick, John M. Usher, James R. Terborg, Laura Poppo, Audredy J. Murrell, Janet M. Dukerich, Deborah Crown Core, Kevin E. Dickson, and Jessica Simmons Jourdan (2001), "Sport and Organizational Studies: Exploring Synergy," Journal of Management Inquiry, 14 (2), 182-210.

Xie, Chunyan, Richard P. Bagozzi, and Sigurd V. Troye (2008), "Trying to Prosume: Toward a Theory of Consumers as Co-Creators of Value," Journal of the Academy of Marketing Science, 36 (1), 109-122.

«NOT CITED / CITE OR DELETE > Zeithaml, Valarie A., Leonard L. Berry, and A. Parasuraman (1996), "The Behavioral Consequence of Service Quality," Journal of Marketing, 60 (2), 31-46. 